DE

M E D I C I N A

T R O P I C A L

$\mathrm{DE}$

SÃO PAULO

JOURNAL OF THE SÃO PAULO INSTITUTE OF TROPICAL MEDICINE

(1) Universidade de São Paulo, Faculdade de Medicina de Ribeirão Preto, Departamento de Clínica Médica, Ribeirão Preto, São Paulo, Brazil

(2)Universidade de São Paulo, Faculdade de Ciências Farmacêuticas de Ribeirão Preto, Ribeirão Preto, São Paulo, Brazil

Correspondence to: Erika Nascimento Universidade de São Paulo, Faculdade de Medicina de Ribeirão Preto, Departamento de Clínica Médica, Av. Bandeirantes, 3900 , Monte Alegre, CEP 14040-900, Ribeirão Preto, SP, Brazil

E-mail: erika.nascimento@gmail.com

Received: 23 November 2016

Accepted: 31 March 2017

\section{Cryptococcus neoformans and $C$. gattii isolates from both HIV-infected and uninfected patients: antifungal susceptibility and outcome of cryptococcal disease}

\author{
Erika Nascimento', Lucia Helena Vitali ${ }^{1}$, Marcia Regina von Zeska Kress ${ }^{2}$, \\ Roberto Martinez ${ }^{1}$
}

\section{ABSTRACT}

One of the factors causing treatment failure in cryptococcosis is the resistance of Cryptococcus spp. to antifungal drugs, which has motivated the susceptibility assessment of isolates from patients with cryptococcosis, different clinical conditions and infections outcomes. Clinical isolates of Cryptococcus spp. from three different groups of patients were studied in the present investigation: $19 \mathrm{HIV}$-positive patients with relapsing and/or refractory meningitis (Group 1), 30 HIV-positive patients who experienced a single and limited episode of cryptococcosis (Group 2), and 19 HIV-negative patients with cryptococcosis (Group 3). Eighty C. neoformans var. grubii isolates and 7 C. gattii isolates were studied. The minimum inhibitory concentration (MIC) of amphotericin B, azole drugs and flucytosine was determined for Cryptococcus spp. by broth microdilution test and E-test. The MIC50 and MIC90 were 0.25 and $0.50 \mu \mathrm{g} / \mathrm{mL}$ for amphotericin B, 4.0 and $8.0 \mu \mathrm{g} / \mathrm{mL}$ for fluconazole, 0.06 and $0.25 \mu \mathrm{g} / \mathrm{mL}$ for itraconazole, 0.25 and $0.50 \mu \mathrm{g} / \mathrm{mL}$ for voriconazole, and 8.0 and $16.0 \mu \mathrm{g} / \mathrm{mL}$ for flucytosine, respectively. Amphotericin B and itraconazole showed higher MICs for C. neoformans var. grubii and C. gattii, respectively. The MICs of fluconazole and itraconazole obtained with the E-test were higher than those obtained with broth microdilution. Isolates from non-HIV coinfected were less sensitive to the azoles. There was no difference in the susceptibility of $C$. neoformans var. grubii isolates from patients with a favorable or unfavorable outcome or along the episodes of relapsing and/or refractory meningitis.

KEYWORDS: Cryptococcal meningitis. Relapsing and refractory cryptococcosis. Cryptococcus spp. Antifungal susceptibility. HIV.

\section{INTRODUCTION}

Cryptococcosis is the second most frequent systemic fungal infection involving HIV-positive patients. It occurs also in other immunosuppression conditions and in immunocompetent individuals ${ }^{1}$. The lethality of cryptococcosis is high even with the use of antifungal drugs. In refractory and/or relapsing cases, neurological sequelae frequently occur in survivors. Cryptococcus neoformans var. grubii and C. gattii are commonly isolated from patients and the most common manifestation is cryptococcal meningitis, occurring in $90 \%$ of the cases ${ }^{2}$. Cryptococcus spp. usually shows susceptibility to amphotericin B, azole drugs and flucytosine ${ }^{3,4}$. Amphotericin $\mathrm{B}$ in combination with flucytosine is recommended for the treatment of cryptococcal meningitis, followed by maintenance therapy with fluconazole ${ }^{2}$. At present, the resistance of Cryptococcus spp. to amphotericin B, fluconazole and flucytosine is less than $1 \%$, but non-susceptible strains have arisen all over the world, suggesting 
progression to a future broader resistance ${ }^{5,6}$. The lack of susceptibility of Cryptococcus spp. to these antifungal agents may be one of the critical factors determining an adverse outcome in patients with cryptococcosis ${ }^{7}$. The assessment of antifungal Cryptococcus spp. susceptibility is recommended in order to plan patient treatment and also to monitor the tendency of resistance to drugs used in clinical practice.

In the present study, previously genotyped isolates ${ }^{8}$ of C. neoformans var. grubii and $C$. gattii were used in order to assess antifungal drugs susceptibility by comparing the broth microdilution test with the E-test among the Cryptococcus species isolated from HIV-negative and HIV-positive, the latter group according to the outcome.

\section{MATERIALS AND METHODS}

\section{Clinical isolates}

A total of 87 Cryptococcus spp. isolates from 68 patients with cryptococcal meningitis were evaluated. The patients were diagnosed and treated at the University Hospital, Ribeirão Preto Medical School, University of São Paulo, Ribeirão Preto, SP, Brazil, from 2000 to 2011. For the comparison of antifungal susceptibility of the isolates, the patients were divided into three groups. Group 1 consisted of the isolates from 19 immunocompromised HIV-positive patients with relapsing and/or refractory cryptococcosis (a total of 38 isolates, 19 of which corresponded to the initial episode of cryptococcosis and 19 to the refractory or relapse period). The refractory or relapse period was defined as the reisolation of Cryptococcus spp. from cerebrospinal fluid (CSF) after a period of negative cultures or as the persistence of isolation of Cryptococcus spp. from CSF after two months of antifungal therapy. Group 2 consisted of 30 isolates (CSF collected before antifungal treatment) from 30 immunocompromised HIV-positive patients who had experienced a single and limited episode of cryptococcosis. Group 3 consisted of 19 Cryptococcus spp. isolates from apparently immunocompetent (11 cases) or immunocompromised HIV-negative patients (8 cases) (in all patients, the CSF was collected before antifungal treatment). The eventual change of $C$. neoformans var. grubii susceptibility was checked in refractory or relapsing cases (Group 1) by comparing the first isolate obtained during the pretreatment phase to the last isolate obtained from each patient after treatment failure ( 2 to 87 month interval between the isolates). The lethality of cryptococcosis was analyzed according to $C$. neoformans susceptibility in 23 patients with AIDS (Groups 1 and 2) treated with amphotericin B for at least one month followed by maintenance therapy with fluconazole. For the outcome analysis, we considered the deaths attributed to complications of cryptococcosis, including bacterial infections that occurred during the induction and consolidation phase and late deaths in cases of relapsing and/or refractory cryptococcal infection.

\section{Microorganisms and growth conditions}

Cryptococcus spp. isolates were previously identified by standard Clinical Mycology methods and also using the automated system Vitek ${ }^{\circledR} 1$ or Vitek ${ }^{\circledR} 2$ (bioMérieux, France) and by using molecular methods ${ }^{8}$. The yeasts were maintained in the laboratory by periodic culture in Sabouraud Dextrose Agar (SDA) medium at $25{ }^{\circ} \mathrm{C}$. A total of 87 Cryptococcus spp. isolates were studied, -80 C. neoformans var. grubii isolates were distributed among group $1(\mathrm{n}=38)$, group $2(\mathrm{n}=29)$, and group $3(\mathrm{n}=13)$. C. gattii $(\mathrm{n}=7)$ were identified in group $2(n=1)$ and group $3(n=9)$.

\section{Antifungal susceptibility testing}

\section{Broth microdilution}

The susceptibility of Cryptococcus spp. isolates to the antifungal drugs was determined by the broth microdilution method according to the M27-A2 protocol (Clinical and Laboratory Standards Institute) ${ }^{9}$. Roswell Park Memorial Institute (RPMI) medium 1640 (Sigma Aldrich Chemical Company, St Louis, MO) containing L-glutamine buffer with $2 \%$ glucose added and buffered with morpholino propanesulfonic acid (MOPS) and $1 \mathrm{M} \mathrm{NaOH}, \mathrm{pH} 7.0$, was added to sterile 96-well flat-bottom plates (TPP, Switzerland). The yeast inoculum was prepared in RPMI culture medium to a final concentration of $2.0 \times 10^{3} \mathrm{CFU} \mathrm{mL}^{-1}$, as recommended by the $\mathrm{M} 27-\mathrm{A} 2^{9}$ document.

The antifungal drugs tested were: amphotericin B, fluconazole, itraconazole, voriconazole, and flucytosine (Sigma Aldrich Chemical Corporation). Amphotericin B, itraconazole and voriconazole were diluted in dimethyl sulfoxide (Sigma Aldrich Chemical Corporation), while fluconazole and flucytosine were dissolved in sterile distilled water. The antifungal drugs were diluted in RPMI medium and serial dilutions were carried out in order to obtain final concentrations of $0.125-64 \mu \mathrm{g} \mathrm{mL}-1$ for flucytosine, $0.125-64 \mu \mathrm{g} \mathrm{mL} \mathrm{m}^{-1}$ for fluconazole and 0.03-16 $\mu \mathrm{g} \mathrm{mL}{ }^{-1}$ for amphotericin B, itraconazole and voriconazole.

The 96-well plates were incubated at $37{ }^{\circ} \mathrm{C}$ for $48 \mathrm{~h}$ and the optical density of each well was measured with a microplate reader (Multiskan MS) adjusted to a wavelength of $492 \mathrm{~nm}$. The minimum inhibitory concentration (MIC) was considered as the lowest concentration capable of inhibiting fungal growth by $\geq 80 \%$ for amphotericin B and by $\geq 50 \%$ for the other antifungal drugs in relation 
to the positive control (CLSI, 2002) ${ }^{9}$. The instrumental reading was confirmed by visual reading. $C$. neoformans ATCC 90112 and Candida parapsilosis ATCC 22019 were included in all tests as positive controls. The MIC values for all drugs were interpreted according to the CLSI M27-A2 protocol. The susceptibility of each Cryptococcus spp. isolate was determined in duplicate.

\section{E-test}

E-test was performed according to the manufacturer's instructions (AB Biodisk - Solna, Sweden). The antifungal drugs tested were itraconazole, fluconazole, voriconazole and amphotericin B. The medium used was RPMI 1640 containing $1.5 \%$ agar, supplemented with $2 \%$ glucose and buffered with MOPS to $\mathrm{pH}$ 7. The yeast inoculum was the same used for the broth microdilution. E-test gradient strips were placed on the surface of a previously inoculated plate by seeding the inoculum on the surface of the agar plate and left to dry for $15 \mathrm{~min}$. The E-test strips had the following gradient of antifungal concentration: 0.002-32.0 $\mu \mathrm{g} \mathrm{mL}-1$ for amphotericin $\mathrm{B}$, itraconazole and voriconazole and 0.016-256 $\mu \mathrm{g} \mathrm{mL} \mathrm{m}^{-1}$ for fluconazole. The plates were incubated at $37^{\circ} \mathrm{C}$ for $48 \mathrm{~h}$. MIC readings were obtained at the point of intersection between the ellipse of growth inhibition and the E-test strip.

\section{Statistical analysis}

The Excel 2007 for Windows software (Microsoft Corp., USA) was used to determine the MIC50 and MIC90 values and the geometric mean. The data for groups 1, 2 and 3 were compared by the Kruskal-Wallis test and the Dunn's post-hoc test. The methods (broth microdilution and E-test), the data for the species (C. neoformans var. grubii and C. gattii) and the data for patient outcome (cure and death) were compared by the Mann-Whitney test using the GraphPad Prism 6 software (San Diego, CA). The level of significance was set at $p<0.05$ in all analysis.

\section{Ethics considerations}

The study was approved by the Research Ethics Committee of the University Hospital, Ribeirão Preto Medical School, University of São Paulo (Protocol HCRP $\mathrm{n}^{\circ} 12247 / 2010$ ).

\section{RESULTS}

\section{Comparison of broth microdilution and E-test methods}

Four antifungal drugs were tested by broth microdilution method and E-test against 61 clinical isolates of $C$. neoformans var. grubii belonging to groups 1,2 and 3 . E-test MICs were higher for fluconazole and itraconazole. In contrast, the MICs for amphotericin $\mathrm{B}$ and voriconazole were higher in broth microdilution method $(\mathrm{p}<0.0001)$ (Table 1).

\section{In vitro susceptibility of $C$. neoformans var. grubii and C. gattii comparison}

Five antifungal drugs were tested by the broth microdilution method in 61 clinical isolates of $C$. neoformans var. grubii and in 7 isolates of $C$. gattii. $C$. neoformans var. grubii was less susceptible to amphotericin B ( $\mathrm{P}=0.0004)$, while $C$. gattii was less susceptible to itraconazole $(\mathrm{P}=0.0114)$ (Table 2$)$.

Comparison of in vitro susceptibility of $C$. neoformans var. grubii according to the patient's group

A significant MIC difference was detected for itraconazole $(\mathrm{P}=0.0186)$ and voriconazole $(\mathrm{p}=0.0022)$ on in vitro susceptibility test. The Dunn's post-test showed that this significant difference was between Group 1 and Group 3 for itraconazole and between Group 2 and Group 3 for voriconazole (Figure 1).

\section{MIC of the antifungal drugs and outcome}

C. neoformans var. grubii showed similar susceptibility to amphotericin $\mathrm{B}(\mathrm{p}=0.2227)$ and to fluconazole $(\mathrm{p}=0.1729)$ in patients with AIDS (Group 1 and 2) whose outcome was death $(n=6)$ or progression to cure $(n=17)$ (Figure 1). C. neoformans var. grubii isolated at the beginning of the treatment and after treatment failure in patients with AIDS and refractory/relapsing cryptococcosis (group 1) have shown no differences in susceptibility to the five antifungal drugs tested (Table 3).

\section{DISCUSSION}

The most relevant result obtained in the present study was that there was no association between progression to relapsing/refractory cryptococcosis in patients with AIDS and the MICs of $C$. neoformans for antifungal drugs. Study limitations were the reduced number of $C$. gattii-infected patients and the small number of cases included in the analysis of the impact of antifungal MIC distribution with respect to the cure vs. death outcome.

As previously observed ${ }^{10}, C$. gattii was less susceptible to azole drugs than $C$. neoformans var. grubii. For this 
Table 1 - Comparative assessment of the antifungal MICs obtained by the broth microdilution method and by the E-test for $C$. neoformans var. grubii isolates (61 isolates)

\begin{tabular}{|c|c|c|c|c|}
\hline \multirow{2}{*}{ Antifungal Drug } & & \multicolumn{3}{|c|}{ Susceptibility test } \\
\hline & & Broth Microdilution & E-test & $p$ value $* \star \star$ \\
\hline \multirow[t]{4}{*}{ Amphotericin B } & MIC Range $(\mu \mathrm{g} / \mathrm{mL})$ & $0.13-0.50$ & $0.047-0.50$ & $<0.0001$ \\
\hline & MIC $50(\mu \mathrm{g} / \mathrm{mL})^{*}$ & 0.25 & 0.19 & \\
\hline & MIC $90(\mu \mathrm{g} / \mathrm{mL})^{*}$ & 0.50 & 0.38 & \\
\hline & G.M $(\mu \mathrm{g} / \mathrm{mL})^{\star \star}$ & 0.30 & 0.20 & \\
\hline \multirow[t]{4}{*}{ Fluconazole } & MIC Range $(\mu \mathrm{g} / \mathrm{mL})$ & $1.0-16.0$ & $0.125-32.0$ & $<0.0001$ \\
\hline & MIC $50(\mu \mathrm{g} / \mathrm{mL})$ & 4.0 & 12.0 & \\
\hline & MIC $90(\mu \mathrm{g} / \mathrm{mL})$ & 8.0 & 16.0 & \\
\hline & G.M $(\mu \mathrm{g} / \mathrm{mL})$ & 4.67 & 12.60 & \\
\hline \multirow[t]{4}{*}{ Itraconazole } & MIC Range $(\mu \mathrm{g} / \mathrm{mL})$ & $0.03-1.0$ & $0.016-2.0$ & $<0.0001$ \\
\hline & MIC $50(\mu \mathrm{g} / \mathrm{mL})$ & 0.06 & 0.38 & \\
\hline & MIC $90(\mu \mathrm{g} / \mathrm{mL})$ & 0.25 & 0.75 & \\
\hline & G.M $(\mathrm{mg} / \mathrm{L})(\mu \mathrm{g} / \mathrm{mL})$ & 0.13 & 0.44 & \\
\hline \multirow[t]{4}{*}{ Voriconazole } & MIC Range $(\mu \mathrm{g} / \mathrm{mL})$ & $0.03-0.50$ & $0.016-0.75$ & $<0.0001$ \\
\hline & MIC $50(\mu \mathrm{g} / \mathrm{mL})$ & 0.25 & 0.094 & \\
\hline & MIC $90(\mu \mathrm{g} / \mathrm{mL})$ & 0.50 & 0.25 & \\
\hline & G.M $(\mu \mathrm{g} / \mathrm{mL})$ & 0.27 & 0.14 & \\
\hline
\end{tabular}

${ }^{*} \mathrm{MIC50}$ and MIC90. the concentration capable of inhibiting the growth of $50 \%$ and $90 \%$ of the isolates, respectively. ${ }^{* *} \mathrm{GM}$ : geometric mean, ${ }^{* * *} p$ value, statistic.

Table 2 - Comparison of the in vitro antifungal susceptibility of $C$. neoformans var. grubii $(\mathrm{n}=61)$ and $C$. gattii $(\mathrm{n}=7)$ by the broth microdilution methods

\begin{tabular}{|c|c|c|c|c|}
\hline \multirow{2}{*}{ Antifungal Drug } & & \multicolumn{3}{|c|}{ Broth Microdilution } \\
\hline & & C. neoformans var.grubii & C. gattii & $p$ value $e^{\star \star *}$ \\
\hline \multirow[t]{4}{*}{ Amphotericin B } & MIC Range $(\mu \mathrm{g} / \mathrm{mL})$ & $0.13-0.50$ & $0.06-0.50$ & 0.0004 \\
\hline & MIC $50(\mu \mathrm{g} / \mathrm{mL})^{*}$ & 0.25 & 0.06 & \\
\hline & $\operatorname{MIC} 90(\mu \mathrm{g} / \mathrm{mL})^{*}$ & 0.50 & 0.13 & \\
\hline & $\mathrm{G} \cdot \mathrm{M}(\mu \mathrm{g} / \mathrm{mL})^{\star *}$ & 0.30 & 0.14 & \\
\hline \multirow[t]{4}{*}{ Fluconazole } & MIC Range $(\mu \mathrm{g} / \mathrm{mL})$ & $1.0-16.0$ & $2.0-16.0$ & 0.1139 \\
\hline & MIC $50(\mu \mathrm{g} / \mathrm{mL})$ & 4.0 & 8.0 & \\
\hline & MIC $90(\mu \mathrm{g} / \mathrm{mL})$ & 8.0 & 8.0 & \\
\hline & G.M $(\mu \mathrm{g} / \mathrm{mL})$ & 4.67 & 7.14 & \\
\hline \multirow[t]{4}{*}{ Itraconazole } & MIC Range $(\mu \mathrm{g} / \mathrm{mL})$ & $0.03-1.0$ & $0.13-0.25$ & 0.0114 \\
\hline & MIC $50(\mu \mathrm{g} / \mathrm{mL})$ & 0.06 & 0.13 & \\
\hline & MIC $90(\mu \mathrm{g} / \mathrm{mL})$ & 0.25 & 0.25 & \\
\hline & G.M $(\mu \mathrm{g} / \mathrm{mL})$ & 0.13 & 0.16 & \\
\hline \multirow[t]{4}{*}{ Voriconazole } & MIC Range $(\mu \mathrm{g} / \mathrm{mL})$ & $0.03-0.50$ & $0.25-0.50$ & 0.0758 \\
\hline & MIC $50(\mu \mathrm{g} / \mathrm{mL})$ & 0.25 & 0.50 & \\
\hline & MIC $90(\mu \mathrm{g} / \mathrm{mL})$ & 0.50 & 0.50 & \\
\hline & G.M $(\mu \mathrm{g} / \mathrm{mL})$ & 0.27 & 0.39 & \\
\hline \multirow[t]{4}{*}{ Flucytosine } & MIC Range $(\mu \mathrm{g} / \mathrm{mL})$ & $4.0-16.0$ & $4.0-16.0$ & 0.7630 \\
\hline & MIC $50(\mu \mathrm{g} / \mathrm{mL})$ & 8.0 & 8.0 & \\
\hline & MIC $90(\mu \mathrm{g} / \mathrm{mL})$ & 16.0 & 16.0 & \\
\hline & G.M $(\mu \mathrm{g} / \mathrm{mL})$ & 8.19 & 7.42 & \\
\hline
\end{tabular}

* MIC50 and MIC90 are the concentrations capable of inhibiting the growth of $50 \%$ and $90 \%$ of the isolates, respectively, ${ }^{* *} \mathrm{GM}$ : geometric means, ${ }^{* * *} p$ value, statistic. 


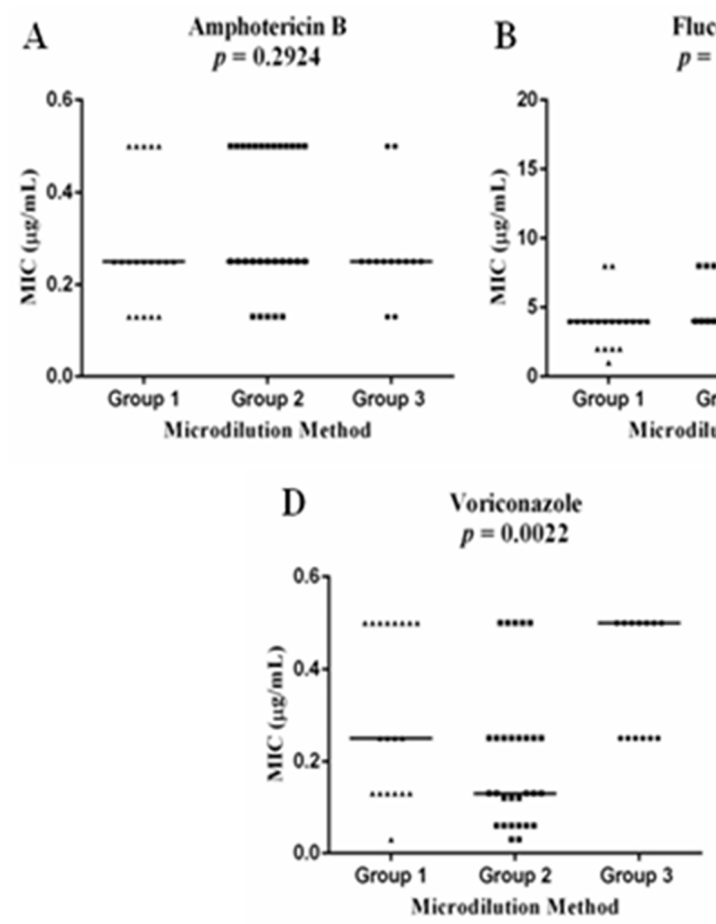

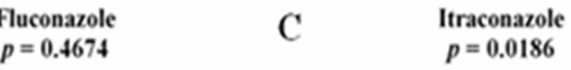
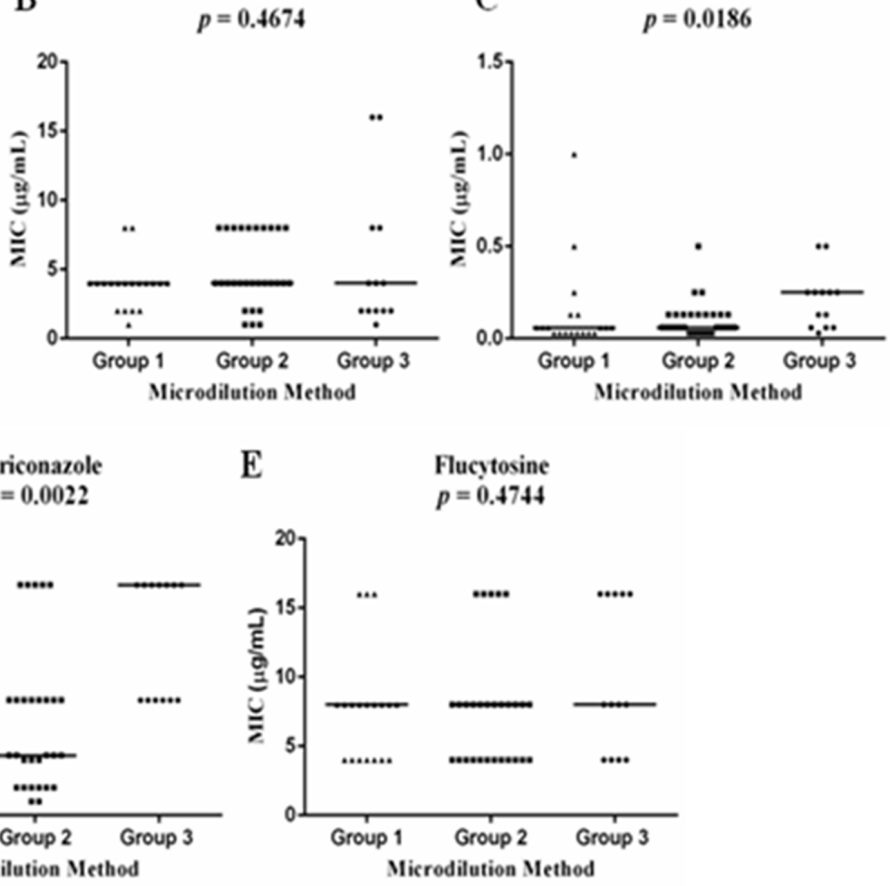

Figure 1 - Comparison of the in vitro susceptibility of $C$. neoformans var. grubii isolates from group $1(n=19), 2$ ( $n=29)$ and 3 $(n=13)$ patients to the antifungal agents amphotericin $B(A)$, fluconazole $(B)$, itraconazole $(C)$, voriconazole $(D)$ and flucytosine $(E)$ by the broth microdilution method. The bars show the mean of the minimum inhibitory concentrations. The $p$-values obtained are represented in the graphs

Table 3 - Antifungal susceptibility of $C$. neoformans var. grubii isolates obtained before treatment and during the period refractory to treatment or during relapse of cryptococcosis from 19 patients with AIDS

\begin{tabular}{|c|c|c|c|c|}
\hline \multirow{2}{*}{ Antifungal Drug } & & \multicolumn{3}{|c|}{ GROUP 1} \\
\hline & & Pretreatment & $\begin{array}{l}\text { Relapse and/or refractory } \\
\text { period }\end{array}$ & $p$ value ${ }^{\star \star \star}$ \\
\hline \multirow[t]{4}{*}{ Amphotericin B } & MIC Range $(\mu \mathrm{g} / \mathrm{mL})$ & $0.13-0.50$ & $0.13-0.50$ & 0.8791 \\
\hline & MIC $50(\mu \mathrm{g} / \mathrm{mL})^{*}$ & 0.25 & 0.25 & \\
\hline & $\operatorname{MIC} 90(\mu \mathrm{g} / \mathrm{mL})^{*}$ & 0.50 & 0.50 & \\
\hline & G.M $(\mu \mathrm{g} / \mathrm{mL})^{\star *}$ & 0.28 & 0.27 & \\
\hline \multirow[t]{4}{*}{ Fluconazole } & MIC Range $(\mu \mathrm{g} / \mathrm{mL})$ & $1.0-8.0$ & $0.13-8.0$ & 0.6290 \\
\hline & MIC $50(\mu \mathrm{g} / \mathrm{mL})$ & 4.0 & 4.0 & \\
\hline & MIC $90(\mu \mathrm{g} / \mathrm{mL})$ & 4.0 & 8.0 & \\
\hline & G.M $(\mu \mathrm{g} / \mathrm{mL})$ & 3.84 & 3.64 & \\
\hline \multirow[t]{4}{*}{ Itraconazole } & MIC Range $(\mu \mathrm{g} / \mathrm{mL})$ & $0.03-1.0$ & $0.03-0.13$ & 0.1973 \\
\hline & MIC $50(\mu \mathrm{g} / \mathrm{mL})$ & 0.06 & 0.06 & \\
\hline & MIC $90(\mu \mathrm{g} / \mathrm{mL})$ & 0.25 & 0.13 & \\
\hline & G.M $(\mu \mathrm{g} / \mathrm{mL})$ & 0.13 & 0.08 & \\
\hline \multirow[t]{4}{*}{ Voriconazole } & MIC Range $(\mu \mathrm{g} / \mathrm{mL})$ & $0.03-0.50$ & $0.25-0.50$ & 0.6102 \\
\hline & MIC $50(\mu \mathrm{g} / \mathrm{mL})$ & 0.25 & 0.25 & \\
\hline & MIC $90(\mu \mathrm{g} / \mathrm{mL})$ & 0.50 & 0.50 & \\
\hline & G.M $(\mu \mathrm{g} / \mathrm{mL})$ & 0.30 & 0.27 & \\
\hline \multirow[t]{4}{*}{ Flucytosine } & MIC Range $(\mu \mathrm{g} / \mathrm{mL})$ & $4.0-16.0$ & $4.0-16.0$ & 0.4888 \\
\hline & MIC $50(\mu \mathrm{g} / \mathrm{mL})$ & 8.0 & 8.0 & \\
\hline & MIC $90(\mu \mathrm{g} / \mathrm{mL})$ & 16.0 & 8.0 & \\
\hline & G.M $(\mu \mathrm{g} / \mathrm{mL})$ & 7.78 & 6.63 & \\
\hline
\end{tabular}

${ }^{*}$ MIC50 and MIC90. the concentrations capable of inhibiting the growth of $50 \%$ and $90 \%$ of the isolates, respectively, ${ }^{* *}$ GM: geometric means, ${ }^{* * *} p$ value, statistic. 
reason and because of the small number of $C$. gattii isolates, only the MICs obtained for C. neoformans var. grubii were related to other clinical and laboratory data. When comparing the methods, higher MIC values for fluconazole and itraconazole were obtained with the E-test than with the CLSI-broth microdilution standardized test ${ }^{9}$. Discordance for azoles has been detected in other studies and has been known since the first determinations of the fluconazole MIC for C. neoformans with the E-test ${ }^{11,12}$. More recently, high concordance was observed between the two methods regarding the MIC of azole drugs ${ }^{5}$. Regarding amphotericin $\mathrm{B}$, the MIC values can be lower when using the E-test than when using broth microdilution. Thus, E-test can better discriminate the susceptibility or resistance to these drugs among C. neoformans strains ${ }^{13}$.

The MIC distribution of the five antifungal drugs tested against $C$. neoformans was similar to that detected for isolates from AIDS patients from other regions ${ }^{14}$ and was also comparable to the susceptibility of isolates with the VNI genotype ${ }^{3}$. Regarding the epidemiological cutoff values (ECV) determined for the five antifungal drugs ${ }^{15,16}$, the $C$. neoformans var. grubii and $C$. gattii isolates evaluated here had antifungal MICs up to the respective ECV or immediately above it. No elevated MIC values that might characterize any of the isolates as resistant were detected. Thus, the isolates tested here in general were susceptible to drugs of clinical use, including amphotericin B, fluconazole and flucytosine. Similar results have been previously reported, showing only a small percentage of strains with reduced susceptibility, particularly to fluconazole and flucytosine ${ }^{7,17}$. The obtained data support the recommendation to perform the Cryptococcus spp. antifungal susceptibility test only in cases of isolates from relapsing/refractory cryptococcosis ${ }^{2}$. Comparison of $C$. neoformans infection in patients with and without AIDS revealed higher MICs for itraconazole and voriconazole in patients not infected with HIV. Cryptococcus isolated from Shangai patients with AIDS showed lower susceptibility to fluconazole than isolates from patients without AIDS ${ }^{18}$. Another study revealed that Cryptococcus isolates from non-HIV patients were less susceptible to flucytosine than isolates from AIDS patients ${ }^{19}$. The lack of specification of the isolate genotype and the heterogeneity of patients without AIDS make it difficult to re-conclude on eventual differences between isolates from patients with AIDS and without HIV infection regarding susceptibility to antifungal drugs.

Separate analysis of AIDS cases did not show a difference in susceptibility between Cryptococcus isolates from patients with relapsing/refractory cryptococcosis and from patients with a good response to antifungal therapy.
The MICs of Cryptococcus isolates obtained from the same patient before and after treatment failure were also similar, showing that reduced susceptibility to antifungal drugs is not an important factor for the progression of cryptococcosis to relapse and/or to a refractory state. The same observation was reported for isolates from South American patients ${ }^{20}$ and those from Vietnam ${ }^{21}$. Conversely, in two other case series, the relapse of cryptococcosis was associated with lower susceptibility to fluconazole ${ }^{22,23}$. Cryptococcus spp. isolated from patients may show heteroresistance when exposed in vivo to azole drugs ${ }^{24}$.

The lethality of cryptococcosis in patients coinfected with HIV and treated with amphotericin and fluconazole was not related to the MIC of these drugs for the pretreatment isolates. The same conclusion was reported in studies on patients from other geographic areas ${ }^{13,20,25}$. Paradoxically, in Taiwanese patients, a MIC for fluconazole above $8 \mu \mathrm{g} \mathrm{mL}{ }^{-1}$ was associated with the cure of cryptococcosis ${ }^{26}$.

In conclusion, $C$. neoformans and $C$. gattii isolated in the present study proved, in general, to be susceptible to the drugs used in antifungal therapy. The MIC distribution of these drugs was not related to the progression of the infection to the condition of relapsing/refractory meningoencephalitis or to death due to fungal infection.

\section{ACKNOWLEDGMENTS}

Erika Nascimento was the recipient of a fellowship from Fundação de Amparo à Pesquisa do Estado de São Paulo (FAPESP) for the execution of the present study (Protocol FAPESP 2010/51932-2).

\section{REFERENCES}

1. Mitchell TG, Perfect JR. Cryptococcosis in the era of AIDS - 100 years after the discovery of Cryptococcus neoformans. Clin Microbiol Rev. 1995;8:515-48.

2. Perfect JR, Dismukes WE, Dromer F, Goldman DL, Graybill JR, Hamill RJ, et al. Clinical practice guidelines for the management of cryptococcal disease: 2010 update by the Infectious Diseases Society of America. Clin Infect Dis. 2010;50:291-322.

3. Trilles L, Meyer W, Wanke B, Guarro J, Lazéra M. Correlation of antifungal susceptibility and molecular type within the Cryptococcus neoformans/C. gattii species complex. Med Mycol. 2012;50:328-32.

4. Figueiredo TP, Lucas RC, Cazzaniga RA, França CN, Segato F, Taglialegna R, et al. Antifungal susceptibility testing and genotyping characterization of Cryptococcus neoformans and gattii isolates from HIV-infected patients of Ribeirão Preto, São Paulo, Brazil. Rev Inst Med Trop Sao Paulo. 2016;58:69. 
5. Mahabeer Y, Chang CC, Naidu D, Dorasamy A, Lewin S, Ndung'u T, et al. Comparison of Etests and Vitek $2^{\circledR}$ to broth microdilution for the susceptibility testing of Cryptococcus neoformans. Diagn Microbiol Infect Dis. 2014;80:294-8.

6. Gullo FP, Rossi SA, Sardi JC, Teodoro VL, Mendes-Giannini MJ, Fusco-Almeida AM. Cryptococcosis: epidemiology, fungal resistance, and new alternatives for treatment. Eur J Clin Microbiol Infect Dis. 2013;32:1377-91.

7. Castanheira M, Messer SA, Rhomberg PR, Pfaller MA. Antifungal susceptibility patterns of a global collection of fungal isolates: results of the SENTRY Antifungal Surveillance Program (2013). Diagn Microbiol Infect Dis. 2016;85:200-4.

8. Nascimento E, Vitali LH, Tonani L, Kress MR, Takayanagui OM, Martinez R. Refractory and/or relapsing cryptococcosis associated with acquired immune deficiency syndrome: clinical features, genotype, and virulence factors of Cryptococcus spp. isolates. Am J Trop Med Hyg. 2016;94:975-81.

9. Clinical and Laboratory Standards Institute. M27-A3 : reference method for broth dilution antifungal susceptibility testing of yeasts. $3^{\text {rd }}$ ed. Wayne: CLSI; 2008.

10. Hagen F, Hare Jensen R, Meis JF, Arendrup MC. Molecular epidemiology and in vitro antifungal susceptibility testing of 108 clinical Cryptococcus neoformans sensu lato and Cryptococcus gattii sensu lato isolates from Denmark. Mycoses. 2016;59:576-84.

11. Tewari A, Behera B, Mathur P, Xess I. Comparative analysis of the Vitek 2 antifungal susceptibility system and E-test with the CLSI M27-A3 broth microdilution method for susceptibility testing of Indian clinical isolates of Cryptococcus neoformans. Mycopathologia. 2012;173:427-33.

12. Chen SC, O'Donell ML, Gordon S, Gilbert GL. Antifungal susceptibility testing using E-test: comparison with the broth macrodilution technique. J Antimicrob Chemother. 1996;37:265-73.

13. Dannaoui E, Abdul M, Arpin M, Michel-Nguyen A, Piens MA, Favel A, et al. Results obtained with various antifungal susceptibility testing methods do not predict early clinical outcome in patients with cryptococcosis. Antimicrob Agents Chemother. 2006;50:2464-70.

14. Souza LK, Fernandes OF, Kobayashi CC, Passos XS, Costa CR, Lemos JA, et al. Antifungal susceptibilities of clinical and environmental isolates of Cryptococcus neoformans in Goiânia city, Goiás, Brazil. Rev Inst Med Trop Sao Paulo. 2005;47:2536.

15. Espinel-Ingroff A, Chowdhary A, Cuenca-Estrella M, Fothergill A, Fuller J, Hagen F, et al. Cryptococcus neoformansCryptococcus gattii species complex: an international study of wild-type susceptibility endpoint distributions and epidemiological cutoff values for amphotericin B and flucytosine. Antimicrob Agents Chemother. 2012;56:3107-13.

16. Espinel-Ingroff A, Aller AI, Canton E, Castañón-Olivares LR,
Chowdhary A, Cordoba S, et al. Cryptococcus neoformansCryptococcus gattii species complex: an international study of wild-type susceptibility endpoint distributions and epidemiological cutoff values for fluconazole, itraconazole, posaconazole, and voriconazole. Antimicrob Agents Chemother. 2012;56:5898-906.

17. Pan W, Khayhan K, Hagen F, Wahyuningsih R, Chakrabarti A, Chowdhary A, et al. Resistance of Asian Cryptococcus neoformans serotype A is confined to few microsatellite genotypes. PLoS One. 2012;7:e32868.

18. Li M, Liao Y, Chen M, Pan W, Weng L. Antifungal susceptibilities of Cryptococcus species complex isolates from AIDS and non-AIDS patients in Southeast China. Braz J Infect Dis. 2012;16:175-9.

19. Arsic Arsenijevic V, Pekmezovic MG, Meis JF, Hagen F. Molecular epidemiology and antifungal susceptibility of Serbian Cryptococcus neoformans isolates. Mycoses. 2014;57:380-7.

20. Agudelo CA, Muñoz C, Ramírez A, Tobón AM, de Bedout Bact C, Cano LE, et al. Response to therapy in patients with cryptococcosis and AIDS: association with in vitro susceptibility to fluconazole. Rev Iberoam Micol. 2015;32:21420.

21. Day JN, Duong VA, Chau TT, Hoang TN, Wolbers M. Relationship of susceptibility testing of Cryptococcus neoformans to survival and mycological clearance in HIV associated cryptococcal meningitis. Mycoses. 2014;57 Suppl 1:106-7.

22. Davey KG, Szekely A, Johnson EM, Warnock DW. Comparison of a new commercial colorimetric microdilution method with a standard method for in-vitro susceptibility testing of Candida spp. and Cryptococcus neoformans. J Antimicrob Chemother. 1998;42:439-44.

23. Bicanic T, Harrison T, Niepieklo A, Dyakopu N, Meintjes G. Symptomatic relapse of HIV-associated cryptococcal meningitis after initial fluconazole monotherapy: the role of fluconazole resistance and immune reconstitution. Clin Infect Dis. 2006;43:1069-73.

24. Sionov E, Chang YC, Kwon-Chung KJ. Azole heteroresistance in Cryptococcus neoformans: emergence of resistant clones with chromosomal disomy in the mouse brain during fluconazole treatment. Antimicrob Agents Chemother. 2013;57:5127-30.

25. Smith KD, Achan B, Hullsiek KH, McDonald TR, Okagaki $\mathrm{LH}$, Alhadab AA, et al. Increased antifungal drug resistance in clinical isolates of Cryptococcus neoformans in Uganda. Antimicrob Agents Chemother. 2015;59:7197-204.

26. Lee CH, Chang TY, Liu JW, Chen FJ, Chien CC, Tang YF, et al. Correlation of antifungal susceptibility with clinical outcomes in patients with cryptococcal meningitis. BMC Infect Dis. 2012;12:361. 